\title{
UNIVERSITY TEACHING IN THE DAYS OF COVID-19
}

\author{
F. Zuccoli, L. Teruggi \\ University of Milano Bicocca (ITALY)
}

\begin{abstract}
We write this paper at a time of worldwide crisis due to the ongoing coronavirus pandemic. University teaching has also been dramatically impacted, and for perhaps the first time, we have had to radically modify our on-campus courses so that they may be followed using exclusively e-learning methods. In relation to our General Didactics module, previously offered in both on-campus and blended learning formats, we have risen to the challenge by completely redesigning the course content and activities, while striving to maintain constant interaction both with and among our students.
\end{abstract}

The entire academic staff of the Degree course in Primary Education at the University of Milan Bicocca received initial training in the use of the university's e-learning platform and its resources. This has been followed by a phase of individual experimentation and discussion with colleagues, and finally an evaluation phase. A key criterion from the outset was that the online classes should be relatively short and not exclusively verbal, but rather should take the form of discrete "instalments" of learning content, focused on clearly defined topics. Learning contents were also to be presented in such a way as to elicit the students' active engagement, both individually and in groups.

In this paper, we outline how we proceeded to redesign both module formats in terms of their content and the use of online tools including forums, chats, and repositories. Our analysis of how the new modules have evolved (and are still evolving) includes the feedback of the students themselves in relation to the new distance modes of delivery and the changes underway in education more generally.

Keywords: teaching, learning, university, e-learning.

\section{INTRODUCTION}

This paper was written as the Covid-19 outbreak was continuing to wield a severe impact worldwide, and especially in Italy. When we first drafted the abstract, we believed that the situation was serious, but that normality would be restored in the space of weeks. However, as time went on, we came to realize that a more radical change was underway: a change that would irreversibly modify our future and that we needed to fully engage with. Day by day, we learned of additional restrictions to our freedom of movement and action, not only as citizens but also as professionals and academics. International, national, regional, civic, and university institutions opted to lock down our places of work, study, and recreation, identifying this as the only possible means of slowing the spread of the virus in the absence of medical alternatives. The radical effects of this strategy have shifted from the sudden closure of all places of encounter to the protraction of social isolation and distancing for an indefinite length of time. As we write, definite arrangements are not even in place for the next academic year. In the short term, we have had to deliver an entire semester of university courses without ever meeting our students: this has entailed redesigning course modules, laboratories, work placements, examination procedures, and in general all the academic activities that were previously routinely conducted on campus. Moving forwards, it is becoming increasingly likely that, for the next academic year, university entrance exams and traditional on-campus courses will again need to be radically revisited. This in effect will mean revolutionizing third level education, which - in the short term at least - will no longer be characterized by lecture theatres packed with students, and hordes of students and staff constantly moving about university buildings, but rather by carefully monitored learning activities that have been designed to facilitate the required level of social distancing. These unstoppable changes, with no clear or immediate prospect of returning to a state of "normality" that will likely be different to the past in any case, have led to the positive re-evaluation of distance learning formats. Online learning methods have played a key role in allowing university education to continue - despite the current uncertainty concerning the ultimate duration of the crisis, and the challenges posed by a constant flow of news stories chronicling advances and setbacks.

One of the most positive aspects of this difficult period has been the determination to keep university education going that has been unanimously displayed by faculty, support staff and students: this has 
underpinned our success to date in identifying the best possible solutions. As the situation has evolved, we have seen an increasing number of academic publications analysing the strategies being brought to bear by different universities in light of the highly complex and all-pervasive effects of the current pandemic. This body of scholarship has been examining university institutions' response to and management of the crisis at multiple levels, including from legal [1], economic [2], educational, didactic, and psychological $[3,4,5]$ perspectives.

\section{FROM SIMPLE EXPERIMENTATION TO COMPLEX CHANGE}

In this paper, we specifically examine changes and developments in the General Didactics module, a core component of the second year of UNIMIB's Master's Degree in Primary Education which offers basic training for primary and nursery school teachers. Prior to the Covid-19 epidemic, given the high number of students enrolled on the module, it was already routinely offered in two alternative formats: one version was delivered entirely on campus, while the other blended on-campus classes with etivities and distance learning methods. The blended course had been designed with a view to facilitating the participation of our many working students, who did not have time to attend many classes on campus, but who saw the course content as key to their ongoing professional development. Both the on-campus and distance activities were designed to stimulate an active learning approach on the part of the students. The blended course, with its practical assignments, scope for encouraging student participation, and emphasis on student voice, had led the academic staff to conclude, in a recent publication, that "from our point of view these experiences allow us to start a process of reflection on university teaching centered on the potential of students as fundamental resources for teaching and learning. Indeed, their active participation [6] through the various proposed activities has been instrumental in confirming the validity of this approach to become reflective teachers [7]" [8, p. 8784].

Although the blended module in General Didactics already made use of distant learning approaches, specifically e-tivities, with the positive outcomes just mentioned, the Covid-19 outbreak has nevertheless made it necessary to redesign its entire format. The fact that no on-campus classes could be held, removing all opportunity for face-to-face communication, real-time back-and-forth exchanges between lecturer and students, non-verbal and para-verbal communication etc. led us to revisit the key course content and the distance learning methods that we would deploy to convey it to our students.

Reviewing the course content entailed selecting a core block of essential learning contents on the theme of "educational action [9, pp.41-81; 10], that is to say the "tools" required by the students to analyse the dynamics of the interaction between teachers, pupils, and knowledge in a given educational and social context. Once the key contents had been chosen, the next challenge was to "didactically transpose" them [9, pp. 197-229]: that is to say, we needed to decide how best to present them via asynchronous video-lessons. In the absence of real-time (verbal and non-verbal) feedback from the students, we needed to create "texts" that would take account of their potential prior knowledge as well as their possible interpretations of the material. This meant constructing oral texts that were differently organized to the text of a typical face-to-face learning session. We therefore produced video-lessons of no longer than $25 / 30$ minutes, which typically made use of real-life events or materials (e.g., a photograph of a classroom, the pages of a copy, a conversation among children, the transcript of a conversation between a teacher and a group of children, etc.) to introduce the target key learning content. In addition to these asynchronous lessons we also planned some synchronous learning sessions, at which we invited in-service primary and kindergarten teachers to share meaningful teaching-learning experiences with our group of student teachers. Students were invited to prepare for the live sessions in advance by viewing a video or reviewing a text from their required reading list. This was done to augment the students' prior knowledge and thereby enhance their learning from the live encounters.

Meanwhile, the traditional version of the General Didactics module had to be redesigned even more drastically, given that prior to the Covid epidemic all classes had been conducted synchronously on campus with a fixed group of some 150 students. This had facilitated: the construction over time of a certain rapport between lecturers and students; the linking of learning contents and points across classes; dialogue and discussion on course themes; small group work and plenary sessions; the use of video and images; , and presentations of real-life projects and experimentation conducted in primary and infant schools, both in Italy and internationally. Again, the Covid-19 epidemic caused the brusque interruption of this teaching-learning programme, which had to be urgently converted into a distance learning format. We immediately decided to respect the usual calendar for the second semester, so 
as to confirm to our students that the module remained on offer and that its ritual timing would be maintained as closely as possible. While this continuity in terms of timing was reassuring for the students, all other aspects of the module had necessarily to be completely redesigned. As in universities all over the world, starting in China early on in the Covid-19 outbreak, we became part of what the researcher Wei Bao has described as a migration towards digital teaching-learning formats. "Since the early spring of 2020, Chinese universities have been experiencing an unprecedented massive "migration" from traditional in-class face-to-face education to online education." [3, p.113]. In our case, implementing this migration involved offering training to our academic staff (lecturers and tutors) in the use of the university's e-learning platform, which prior to the pandemic had only been utilized to a fraction of its potential. In previous academic years, the academic staff of the on-campus module had used it to store materials - from slides with lecture notes, to background reading (articles or books) - or to communicate directly with students. The teachers of the blended module on the other hand had used it far more extensively to hold classes, host forums, and store the students' project work. Shifting to a $100 \%$ distance learning format meant that the teachers of the former on-campus module also began to use the platform to communicate directly with students. We decided that lessons would be asynchronous only, lasting 20-40-minute max, focused on a single topic, presented in extremely clear and simple language, and posing many questions designed to stimulate the students to actively reflect on the target learning content. These asynchronous classes were supplemented by a set of resource materials on the target learning topics: images and videos; short journal articles from the Italian and international scientific literature; extracts of books; open access books and journals. The students were given fortnightly assignments on the target learning topics to be conducted individually or in pairs, after which they were invited to share their personal reflections with the rest of the class. No marks were assigned for this work, rather the emphasis was on generating a fruitful exchange of ideas among the students. The academic staff invested a significant amount of time in preparing materials suited to an exclusively distance learning format. The students' progress was constantly monitored via email. The students made frequent email contact with academic staff to express their opinions and/or request supplementary information and clarification.

\section{STUDENT SURVEY}

Following the implementation of the General Didactics module, the students enrolled on each of the two formats (ex-blended and ex-on-campus) were invited to compile a questionnaire designed by the academic staff to obtain their feedback. Our aim was to give voice to the students and gather their ideas about how to adapt and improve the new offerings, which had been designed and implemented over an unusually short time span, compared to more established formats, as an initial response to the emergency. The survey was conducted in early May, immediately on completion of the two courses. The students were given five days to return it. The questionnaire, which was developed ad hoc following a discussion among the academic staff, included both closed- and open-ended questions [11, pp. 115-142; 12, pp.350-365] and was administered using Google Forms. Completed questionnaires were submitted by 116 students enrolled on the on-campus module and by 101 students enrolled on the blended module. All were studying to become infant school or primary school teachers.

The purpose of the questionnaire was to evaluate the students' level of satisfaction with the module they had just completed, and to elicit their feedback on its various learning contents and environments, as well as their own personal ideas about distant learning (in some cases based entirely on their experience at university and in others also based on their experience as substitute teachers in schools). The instrument comprised three questions, the first two of which concerned different aspects of the General Didactics module they had just taken. The students were presented with multiple responses, including an "other" option which they could define in their own words, and were invited to rate their level of agreement/satisfaction with each response on a scale of 1-5. Among the most striking outcomes was the students' response to the first question: When you compare this module to the on-campus modules you attended up to last semester, what did you miss the most? The students tended to answer very differently depending on whether they had previously attended the on-campus or the blended course.

The following two graphs illustrate the different levels of importance attributed to contact with fellow students by the ex-blended format students (Graph 1) compared to the ex-on-campus format students (Graph 2), respectively. This difference may be attributed to the fact that the latter had been used to meeting their classmates every day, both while taking classes and while studying together for exams. The former, in contrast, were mainly working students, with little time or opportunity to meet with 
classmates. Indeed, the students enrolled on the blended module would sit simply sit their examinations as external candidates if no blended learning option were available to them.

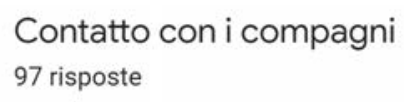

30

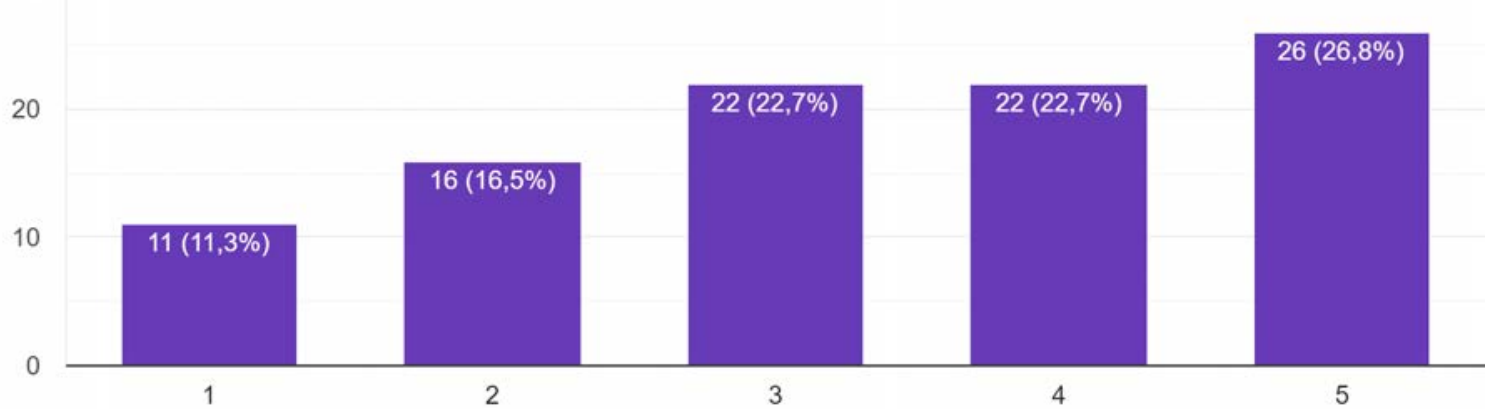

Graph 1 Contact with classmates (97 respondents)

\section{Contatto con i compagni}

115 risposte

80

60

40

20

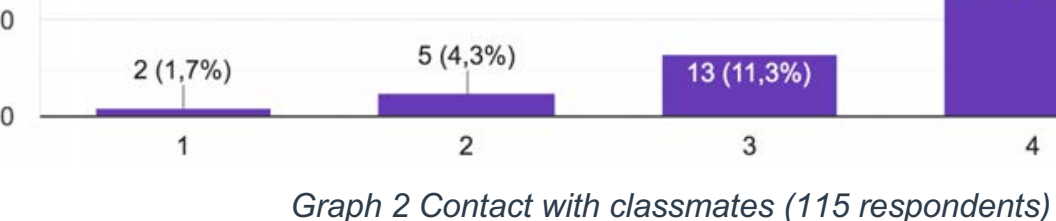

The next two graphs ( 3 and 4) compare the two groups' levels of satisfaction with the asynchronous lessons. They show that over $70 \%$ of the students enrolled on both courses reported a high level of satisfaction (rating of 4 or 5) with these video lectures. The shortness of the videos and the convenience of being able to download and view them in the students' own time were the main reasons for their popularity.

Video lezione in streaming asincrona

98 risposte

60

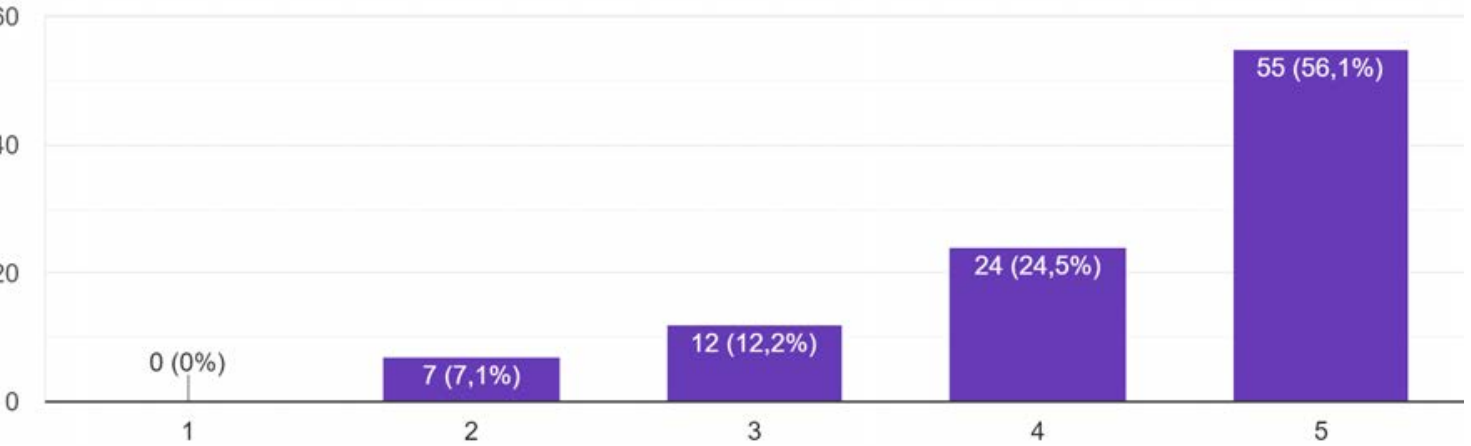

Graph 3 Asynchronous video lessons (98 respondents) 


\section{Video lezione in streaming asincrona \\ 114 risposte}

60

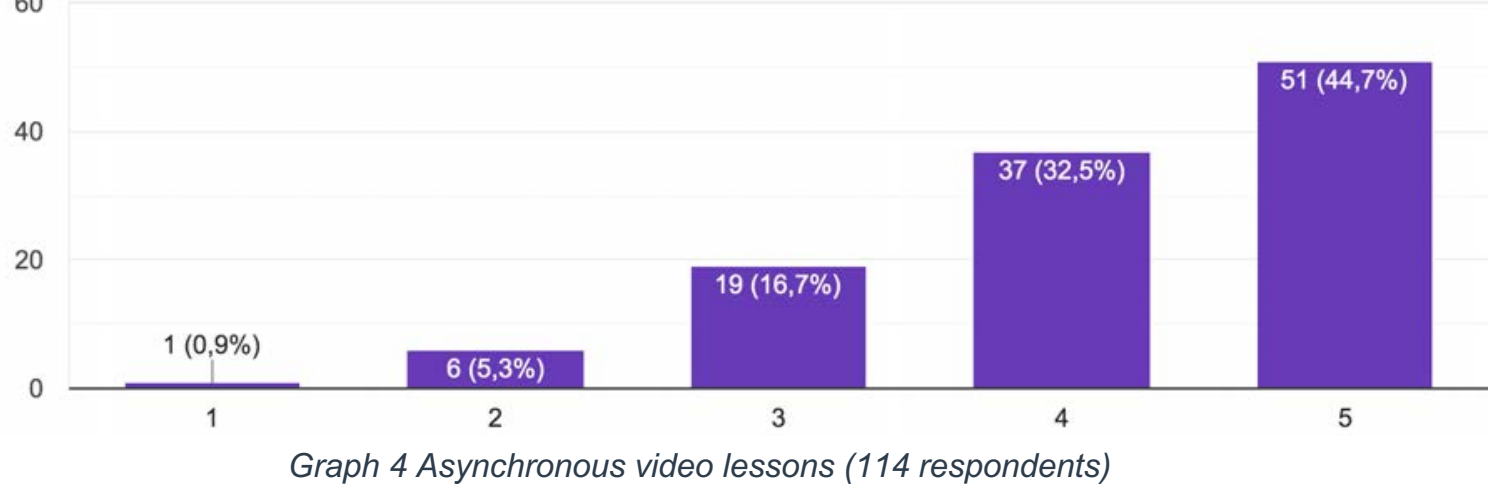

Graph 4 Asynchronous video lessons (114 respondents)

Finally, only the students enrolled on the on-campus module were asked for their views about the implication of the pandemic for distance education in both universities and schools. More specifically, the questionnaire item asked: "Has this period of distance learning given you the opportunity to reflect on technology and its use in education? The possible replies, as shown in the graph below, included: Yes, in fact:

1 I have always believed in the value of using new technologies in schools and this period has confirmed this idea for me (blu 15,2\%).

2 I have realized the importance of receiving teacher training in this specific area (red $45,5 \%$ ).

3 I believe that there is no turning back now: all children should have access to distance learning and we must ensure that this comes about (orange 8,9\%).

4 As a university student, I would like a distance learning option to remain available in the future (green $25 \%$ ).

Under the Other response option, many students took pains to emphasize the importance of face-toface teaching/learning, which they view as continuing to be essential going forward.

Si, infatti, ...

112 risposte

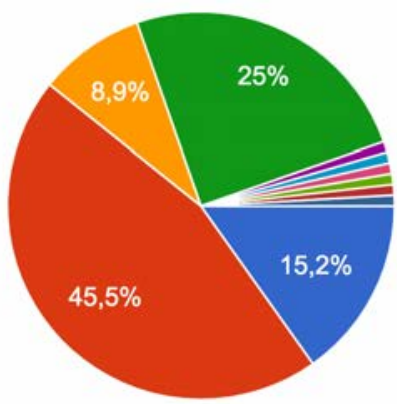

ho sempre creduto nel valore delle nu..

ho capito l'importanza di avere una for..

credo che non si potrà più tornare indi..

come studente universitario vorrei orm...

Ė importante connettersi sempre e in t..

Ho capito la loro importanza poichè h...

Ho capito l'importanza delle competen..

credo nel valore che questi strumenti...

$1 / 2$

5 Students thoughts about distance learning

A careful analysis of all the responses to this item suggests that the students' are on the whole in favour of making greater use of distance learning going forward, in the sense of exploiting more fully its potential and the rich range of educational offerings offered by university e-learning platforms among others. The students have perceived this recent period as a time of change, and are appreciative of the efforts made by their university teachers, whom they view as in the process of learning to use technology with a view to developing suitable teaching methods for distance education. However, the ex-on-campus students especially emphasized the key importance of remaining in contact with their fellow students, a contact that is currently at risk of fragmentation. Distance learning makes it impossible to replicate the rich network of relations that are fostered by the on-campus large classroom setting. With regard to teaching children, the students believed that the face-to-face 
dimension of the learning experience is of vital importance and were concerned about what steps need to be taken to ensure that this dimension can be maintained in the future.

\subsection{The risks associated with the use of digital devices}

One strongly perceived risk concerns the generation of a further barrier to accessing education, linked to students' economic status and whether or not they can afford adequate digital devices and Internet connections. This aspect has been monitored closely in Italy for students attending compulsory education [13] but to date has not been systematically addressed by third-level institutions. This potential equality gap could also affect access to university courses, especially if entrance exams are administered online. The risk that a large segment of the population might thus be prevented from entering third-level education - given that the economic status of students and their families will affect their access to technology as well as their ability to pay university fees - should not be overlooked.

\section{CONCLUSIONS}

The current pandemic is having a worldwide impact and directly influencing school and university education. Our initial impression is that education will be profoundly affected over the long term, in terms of both content and teaching-learning methods. In relation to the two General Didactics modules analysed in this paper, one which previously catered for full-time students who attended classes on campus, and the other which blended periodic on-campus sessions with e-tivities, have both had to be radically redesigned in response to the crisis. On completion of the redesigned modules, we - as the teachers of these modules - have conducted a preliminary analysis of the outcomes, primarily by eliciting the feedback of the students themselves. Our main findings are that: the students who had previously signed up for the blended module report feeling less affected by the reduction in contact with their classmates, an aspect that remains of crucial importance for the students who previously took their courses on campus; both groups of students reported a high level of satisfaction with the asynchronous video lectures, as they could view in their own time and not at pre-programmed times. Again, all respondents expressed satisfaction with the group and pair work, the course materials, and the opportunities that had been provided for dialogue and discussion. This initial feedback, collected immediately after the students had completed the new distance modules, suggests the need to continue analysing distance education methods over the coming months with a view to more fully teasing out their potential and limitations, in the hopes that it will be possible in any event to resume on-campus teaching at least in part.

\section{REFERENCES}

[1] M.H. Khetarpal, S.D. Friedfel, J.J. DiPalma, W.S. Yoshigai, S.M. Ojo SM., "Coronavirus (COVID19) FAQs for Higher Education Employers. Venulex Legal Summaries", April:1-3. https://search.ebscohost.com/login.aspx?direct=true\&db=bth\&AN=142745523\&lang=it\&site=edslive\&scope=site. Accessed May 4, 2020.

[2] M. lansiti, G. Richards, "Coronavirus Is Widening the Corporate Digital Divide", Harvard Business Review Digital Articles, pp.2-4, 2020.

[3] W. Bao, "COVID-19 and online teaching in higher education: A case study of Peking University", Human Behavior \& Emerging Technologies, 2(2), pp.113-115, 2020.

[4] T. Jowsey, G. Foster, P. Cooper-loelu, S. Jacobs, "«Blended learning via distance» in preregistration nursing education: A scoping review", Nurse Education in Practice, 44, 102775. https://doi.org/10.1016/j.nepr.2020.102775, 2020.

[5] F. J. de O. Araújo, L. S. A. de Lima, P. I. M. Cidade, C. B. Nobre, M. L. R. Neto, "Impact of SarsCov-2 And Its Reverberation In Global Higher Education And Mental Health", Psychiatry Research, 288. https://doi.org/10.1016/j.psychres.2020.112977, 2020.

[6] J. Dewey, Education and Experience. New York, NY: Touchstone, (Original work published 1938), 1997.

[7] D. A. Schön, Formare il professionista riflessivo: per una nuova prospettiva della formazione e dell'apprendimento nelle professioni. Milan: Franco Angeli, (Original work published 1986), 2006. 
[8] F. Zuccoli, L. Teruggi, "«Rethinking university teaching" a reflection on the blended general didactics course", in Proceedings of INTED2020 Conference 2nd-4th March, Valencia, Spain, pp. 8781-8784, 2020.

[9] E. Nigris, L. Teruggi, F. Zuccoli (eds.), Didattica generale. Milan-Turin: Pearson, 2016.

[10] P.C. Rivoltella, P.G. Rossi (eds.), L'agire didattico. Brescia: La Scuola, 2012.

[11] E. Gattico, S. Mantovani (eds.), La ricerca sul campo in educazione. I metodi quantitativi. Milan: Bruno Mondadori, 1998.

[12] G. Pastori, In ricerca. Prospettive e strumenti per educatori e insegnanti. Parma: Edizioni JuniorSpaggiari, 2017.

[13] S. Pasta, "Il rischio di allargare la forbice tra Gianni e Pierino. La scuola a distanza: attenzione al divario digitale", Essere a scuola, (numero speciale, marzo): pp. 27-29, 2020. 